\title{
Uma história do esporte para um país esportivo
}

\section{Apresentação \\ Victor Andrade de Melo[1] e Marcelo Bittencourt[2]}

\begin{abstract}
Precisamente o que os historiadores sociais do esporte fazem? Eles examinam os esportes como textos, formações ou práticas sociais, com o propósito de entender ambos, sociedade e esporte. Perguntam e respondem sobre a natureza e formato do esporte em certos períodos, sobre como e por que se concebem formas particulares de praticá-lo, sobre os signi!cados que os agentes humanos a ele concedem, sobre con"itos e contestações que existem ao seu redor, sobre padrões de continuidade e de mudanças nas experiências e estruturas esportivas e sobre o signi!cado social das práticas esportivas no contexto de outras práticas, processos e dinâmicas. ${ }^{1}$
\end{abstract}

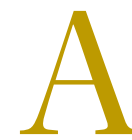

organização de um campo de investigação histórica tendo por objeto as práticas corporais institucionalizadas, ${ }^{2}$ notadamente o esporte, no cenário internacional, data da virada dos anos 1960 e 1970. Já no Brasil, ainda que desde o século XIX existam experiências ligadas à 'preservação' da memória de diferentes modalidades esportivas, foi apenas na década de 1990 que surgiram os primeiros sinais de uma maior estruturação dos estudos históricos que se debruçam sobre tais objetos. ${ }^{3}$ Naquele momento, há pelo menos uma década, outras disciplinas das ciências sociais, notadamente a Antropologia e a Sociologia, já dedicavam uma atenção maior ao desdobramento das investigações pioneiras de José Sérgio Leite Lopes, Simoni Guedes e Roberto DaMatta.

No Brasil, as primeiras iniciativas de conformação da "História do Esporte" - utiliza-se uma metonímia para designar práticas corporais institucionalizadas — não se iniciaram na disciplina História, mas sim no âmbito da Educação Física. Na primeira persistiam desconfianças relativas à propriedade do tema, bastante semelhantes às que existiam com outros objetos que interessavam

\footnotetext{
"Nancy Struna, "Social History and sport", In: Jay Coakley; Eric Dunning, Handbook of Sports Studies, London, Sage, 2007, p. 187-203

${ }^{2}$ Certas práticas corporais, mesmo com peculiaridades, passaram por processos aproximados deinstitucionalização, constituição de um campo ao seu redor, podendo ser investigadas por áreas de pesquisa específicas: esporte, educação física (entendida tanto como disciplina escolar quanto uma área de conhecimento), ginástica, dança, atividades físicas alternativas (antiginástica, eutonia, ioga etc.), alguns fenômenos análogos de períodos anteriores à Era Moderna (as práticas de gregos, os gladiadores romanos, os torneios medievais, um grande número de manifestações lúdicas de longa existência), entre outras (como a capoeira).

3Para mais informações, ver Victor Andrade De Melo; Rafael Fortes, "Sports history in Brazil: an overview and perspectives", Sport History Review, vol. 42, n. 2, p. 102-116,2011.
} 
mais aos historiadores culturais. ${ }^{4}$ A segunda passava por um movimento de reavaliação, que induziu a uma maior proximidade com os estudos socioculturais, contrapondo, ao menos momentaneamente, a forte relação que existia na área com as investigações experimentais de natureza biomédica.

Uma maior proximidade entre a História do Esporte e a História foi observada apenas na primeira década do século XXI. Como indícios, é possível apontar a criação de simpósios temáticos nos eventos organizados pela Associação Nacional de História, a maior presença do tema em revistas especializadas $^{5}$ ou de divulgação científica, o crescimento do número de dissertações, teses e livros acadêmicos sobre o assunto, entre outros.

Esse acolhimento tem certamente relação com as mudanças notadas na disciplina-mãe, que tem demonstrado maior abertura a novas possibilidades de investigação, bem como com os movimentos de consolidação da História do Esporte, sobretudo no decorrer das duas últimas décadas, quando o aperfeiçoamento de suas experiências foi percebido.

Tanto ou mais do que esses dois aspectos, deve-se considerar também a força do fenômeno esportivo na sociedade brasileira. O que era notável nos anos finais do século XIX e cresceu no decorrer do XX teve mais importância na primeira década do XXI, não só em função de o esporte ter se tornado um dos principais produtos dos meios de comunicação e da indústria de entretenimento como um todo, como também pelo fato de que o Brasil, na esteira de seu crescimento econômico e do aumento de sua visibilidade no cenário internacional, sediará os dois maiores eventos esportivos mundiais - a Copa do Mundo de Futebol e os Jogos Olímpicos de Verão.

Nesse país tão e cada vez mais esportivo, não surpreende que o assunto tenha se imposto aos intelectuais e pesquisadores, inclusive aos historiadores, filhos atentos do seu tempo, como sugeria Lucien Febvre.

Este dossiê intenta apresentar um panorama desse campo de investigação nos últimos anos. Sua estruturação partiu de um olhar sobre as discussões que majoritariamente vêm ocorrendo em eventos e periódicos científicos, bem como sobre os caminhos que tal subdisciplina pode vir a trilhar.

A edição inicia-se com uma contribuição de Wray Vamplew, professor emérito da Universidade de Stirling, na Escócia/Reino Unido, autor de livros-referência (entre os quais o renomado "Pay up and play the game: professional sport in Britain, 1875-1914") e editor de importantes periódicos especializados (atualmente está à frente do International Journal of Sport History). Por sua carreira destacada, na qual sobressaem suas contribuições para a história econômica do esporte, em 2011, recebeu o prêmio do ano da International Society of History of Physical Education and Sport (ISHPES). Sua análise da configuração da História do Esporte no cenário internacional é certamente um contributo para que olhemos ao nosso movimento nacional, uma base que pode nos ajudar em caminhadas futuras.

Na sequência, dois jovens pesquisadores, João Manuel Casquinha Malaia Santos (Universidade Nove de Julho, em São Paulo), um especialista

\footnotetext{
4Para um debate sobre a pequena presença do tema na história brasileira até os anos 1990, ver Patrícia Genovez, "O desafio de Clio: o esporte como objeto de estudo da História", Lecturas: Educación Física y Deportes, Buenos Aires, n. 9, 1998.

${ }^{5}$ Desde 2008 existe um periódico integralmente dedicado ao tema, a Recorde: Revista de História do Esporte.
} 
em história econômica do esporte, e Maurício Drumond (Sport: Laboratório de História do Esporte, Universidade Federal do Rio de Janeiro, no Rio de Janeiro), que tem dado significativas contribuições à história política do esporte, fazem uma instigante e perspicaz análise da historiografia do futebol no Brasil. Como em alguns momentos esse foi praticamente o único tema investigado (ainda é o majoritário, mas já divide espaço com outras modalidades), fazia-se necessária tal abordagem, mesmo porque os modelos de pesquisa adotados para discutir o tema, não poucas vezes com imprecisões ou inadequações, foram e têm sido inspiração para muitos estudos.

Cleber Dias, pesquisador da Universidade Federal de Minas Gerais, que tem se dedicado desde seu curso de Mestrado a discutir as relações entre o esporte e o espaço urbano, faz um balanço crítico de um dos objetos mais abordados nessa primeira década de estudos históricos: o surgimento do fenômeno esportivo nas mais diversas cidades brasileiras. Compreender melhor a peculiaridade de cada uma dessas experiências é um desafio fundamental para que possam ser evitadas posturas etnocêntricas e possam ser compreendidas a plasticidade e a riqueza da prática.

Silvana Vilodre Goellner, da Universidade Federal do Rio Grande do Sul, discute um dos temas mais comuns nos estudos históricos do esporte no Brasil e no mundo: as questões de gênero. A pesquisadora alerta para a necessidade de ampliar o escopo das investigações, não as restringindo a análises sobre mulheres. Faz-se necessário não só enfatizar o aspecto relacional, sugerindo-se até mesmo um olhar mais atento às questões da masculinidade, como também levar em consideração outros grupos como homossexuais e transgêneros.

Augusto Nascimento, pesquisador do Instituto de Investigação Científica Tropical/Lisboa, que estuda a história de São Tomé e Príncipe, e Andrea Marzano, da Universidade Federal do Estado do Rio de Janeiro - Unirio, que desenvolve pesquisas sobre a história angolana, lançam um olhar panorâmico sobre a presença e a importância do esporte nas antigas colônias portuguesas na África. Destaca-se a postura dos autores em se afastar de abordagens maniqueístas, percebendo o quanto a prática foi, por ambos os lados, metrópole e movimentos nativistas, mobilizada para seus intuitos específicos.

Enquanto os artigos anteriores são balanços historiográficos de ramos específicos do campo da história do esporte, os dois seguintes são estudos de caso, o primeiro escrito com o uso de fontes documentais, o segundo a partir de um trabalho de campo de natureza antropológica.

Victor Andrade de Melo, coordenador do Sport - Laboratório de História do Esporte e do Lazer, e Marcelo Bittencourt, especialista na história de Angola, debruçam-se sobre a política colonial portuguesa, analisando o Boletim Geral do Ultramar e prospectando o quanto o Estado Novo, à busca de manter seu Império, operou a prática esportiva.

Vale lembrar que os dois artigos anteriores são frutos de um projeto que está em andamento desde 2008, desenvolvido por pesquisadores de três instituições brasileiras e duas de Portugal. Seu principal intuito é investigar, de forma comparativa, a presença do esporte nos países de língua oficial portuguesa. A ambição de tal pesquisa é, portanto, extrapolar as fronteiras nacionais, percebendo-se similaridades e diferenças entre localidades que têm algum grau de relação histórica. 
Para encerrar a publicação, Marcos Alvito, coordenador do Núcleo de Estudos e Pesquisa sobre Esporte e Sociedade da Universidade Federal Fluminense, analisa um tema urgente e de grande visibilidade, as torcidas organizadas, as quais nos últimos anos têm estado constantemente presentes nos meios de comunicação, não poucas vezes sendo tratadas de forma apressada e preconceituosa. O autor chama a atenção para a necessidade de melhor considerar essa que é uma das facetas mais conhecidas e importantes do fenômeno esportivo.

Distintas abordagens metodológicas (Histórias Comparada, Social, Cultural e Política), diferentes recortes espaciais (Brasil, África, Portugal, cenário internacional), diversos temas, oito instituições universitárias de três países: acredita-se que se trata de um bom panorama dos estudos históricos sobre o esporte.

No entanto, não se equivoque o leitor, muita coisa ficou de fora: temas, abordagens, modalidades e investigações espalhadas por todo o país. A diversidade desse alvissareiro campo de pesquisa efetivamente não caberia na íntegra nas dimensões reduzidas de um dossiê. O que é observado no presente trabalho é a ponta de um iceberg, que, ao contrário do que comumente ocorre com esses enormes blocos de gelo, cresce enquanto navega pelas águas de Clio. 